\title{
Developmental Changes in Gastric Fundus Smooth Muscle Contractility and Involvement of Extracellular Calcium in Fetal and Adult Guinea Pigs
}

\author{
DAVID A. PAUL, JANE A. IERARDI, HENRY P. PARKMAN, AND JAMES P. RYAN \\ Department of Pediatrics, Section of Neonatal Medicine, St. Christopher's Hospital for Children \\ and Temple University School of Medicine, Philadelphia, Pennsylvania 19134 [D.A.P., J.A.I.], \\ Department of Medicine, Section of Gastroenterology [H.P.P.], and Department of Physiology \\ [J.P.R.], Temple University School of Medicine, Philadelphia, Pennsylvania 19140
}

\begin{abstract}
Delayed gastric emptying is a common problem in preterm infants. The factors underlying this gastroparesis remain unsettled but may involve immaturity of smooth muscle contraction. The present study was designed to test this hypothesis. Muscle strips from the gastric fundus of fetal and adult guinea pigs were studied in vitro for their contractile response to receptor activation (acetylcholine and bethanechol) and membrane depolarization (potassium chloride). The dose-response curves were analyzed for differences in active force development $\left(\mathrm{kg} / \mathrm{cm}^{2}\right)$. The role of extracellular calcium $\left(\mathrm{Ca}^{2+}\right)$ in the contractile responses was determined by contracting the tissues in a zero- $\mathrm{Ca}^{2+}$ physiologic saline solution and in the presence of nifedipine, a voltage-dependent $\mathrm{Ca}^{2+}$ channel blocker. The results demonstrate the following: 1) tissues from adult animals developed significantly more active force when tested with acetylcholine, bethanechol, and potassium chloride; 2) tissues from the fetal animals were relatively unrespon-
\end{abstract}

\section{ABSTRACT}

sive to contraction with potassium chloride compared with the adult; and 3) both nifedipine and incubation in a zero$\mathrm{Ca}^{2+}$ physiologic saline solution had a significantly greater inhibitory effect on the contractions of adult than fetal muscle strips. Our data indicate that smooth muscle in the gastric fundus develops increasing force with maturation. The increased contractility in the adult fundus appears to be due to an increased involvement of extracellular calcium influx, in part through voltage-dependent $\mathrm{Ca}^{2+}$ channels. (Pediatr Res 36: 642-646, 1994)

ACh, acetylcholine

\section{Abbreviations}

BETH, bethanechol

$\mathbf{K C l}$, potassium chloride

PSS, physiologic saline solution

$\mathbf{L}_{\mathbf{o}}$, length at which maximal active force occurred $\mathrm{Ca}^{2+}$, calcium
Delayed gastric emptying is a common problem in preterm infants $(1,2)$. The factors underlying this gastroparesis remain unsettled but may involve the neural, hormonal, or myogenic factors that control gastric motility. Antral gastric smooth muscle from newborn animals has previously been shown to develop less active force than muscle from adult animals (3-5) and has been demonstrated to undergo a period of postnatal maturation with respect to agonist sensitivity (5), quantity of $\mathrm{Ca}^{2+}$ channels (4), and the utilization of $\mathrm{Ca}^{2+}(4,6)$. However, to our knowledge, the contractile properties of the fetal gastric fundus have not been extensively characterized.

The purpose of this study was to determine whether differences were present in the force development of the

Received February 14, 1994; accepted June 30, 1994.

Correspondence: David A. Paul, M.D., Medical Center of Delaware, Section of Neonatology, P.O. Box 6001, Newark, DE 19718. gastric fundus of the adult and third-trimester fetal guinea pig. The in vitro contractile responses of adult and fetal animals to receptor-dependent agonists, $\mathrm{ACh}$ and $\mathrm{BETH}$, and a receptor-independent agonist, $\mathrm{KCl}$, were compared. The involvement of extracellular and intracellular $\mathrm{Ca}^{2+}$ stores in the contractile response was investigated by 1 ) contracting the tissues in the presence of nifedipine, a voltage-dependent $\mathrm{Ca}^{2+}$ channel blocker, 2) contracting the tissues in a zero- $\mathrm{Ca}^{2+} \mathrm{PSS}$, and 3) isolating the contribution of intracellular $\mathrm{Ca}^{2+}$ sources to contraction.

\section{METHODS}

\section{Tissue Preparation}

Muscle strips were obtained from the gastric fundus of fetal (third-trimester, crown-rump length 10-12 cm) and adult (female, $600-650 \mathrm{~g}$ ) guinea pigs. The stomachs were 
removed through a midline incision and opened along the greater curvature. The fetal animals were obtained by killing the mother and rapidly performing a cesarean section. The stomachs were pinned flat in a dissecting dish filled with warmed $\left(37^{\circ} \mathrm{C}\right)$, oxygenated $(100 \%)$ PSS. With the aid of a stereomicroscope, the fundus was identified and full-thickness muscle strips were prepared by careful separation of the muscle from the mucosal layers. The muscle strips were cut parallel to the circular muscle layer.

The muscle strips were mounted in individual $10-\mathrm{mL}$ tissue baths filled with warmed $\left(37^{\circ} \mathrm{C}\right)$, oxygenated $(100 \%)$ PSS. One end of each strip was connected by a metal rod to a force transducer (FT-03C, Grass Instrument Co., Quincy, MA), and the other was attached to a glass rod. After a 1-h equilibration period, the muscle strip $\mathrm{L}_{\mathrm{o}}$ was determined for each strip as described previously $(3,7)$. All experiments were performed at $L_{o}$. A permanent record of the force developed by each strip was obtained using a Grass multichannel polygraph.

At the completion of each experiment, the length and weight of each muscle strip was determined and used to calculate the cross-sectional area of the preparation from the following relationship: cross-sectional area $=$ mass/ length $\times$ density, where length is measured at $L_{o}$ and density is assumed to be $1.05 \mathrm{~g} / \mathrm{cm}^{2}(8)$. The accuracy of this method for determining cross-sectional surface area has been previously verified using optically derived measurements (9). All contractile force was normalized to muscle cross-sectional area and expressed as $\mathrm{kg} / \mathrm{cm}^{2}(3)$.

\section{Solutions}

Normal PSS. The PSS contained the following (in $\mathrm{mM}$ ): $137.5 \mathrm{NaCl}, 5.0 \mathrm{KCl}, 1.0 \mathrm{MgCl}_{2}, 1.5 \mathrm{CaCl}_{2}, 10.0 \mathrm{dex}-$ trose, and 5.0 N-2-hydroxyethylpiperazine- $\mathrm{N}^{\prime}$-2-ethanesulfonic acid (HEPES). All solutions were titrated to $\mathrm{pH}$ 7.4 with $\mathrm{NaOH}$ and gassed with $100 \% \mathrm{O}_{2}$.

$\mathrm{Ca}^{2+}$-free PSS. Ca ${ }^{2+}$-free PSS was prepared by eliminating $\mathrm{CaCl}_{2}$ from the buffer medium and substituting an equivalent amount of $\mathrm{NaCl}$. EGTA was added to a final concentration of $0.1 \mathrm{mM}$ as previously described (10).

High- $\boldsymbol{K}^{+}$PSS. High- $\mathrm{K}^{+}$solutions $(10$ to $80 \mathrm{mM}$ ) were prepared by increasing the $\mathrm{KCl}$ in the normal PSS to the desired concentration. The $\mathrm{NaCl}$ concentration was reduced to maintain osmolarity.

Chemicals. HEPES, EGTA, nifedipine, ACh, and BETH were obtained from Sigma Chemical Co. (St. Louis, MO).

\section{Experimental Protocol}

Dose-response experiments. The muscle strips were examined for their contractile response to $\mathrm{ACh}\left(10^{-8}\right.$ to $10^{-3}$ $\mathrm{M})$, BETH $\left(10^{-8}\right.$ to $\left.10^{-3} \mathrm{M}\right)$, and $\mathrm{KCl}(10$ to $80 \mathrm{mM})$. ACh and BETH dose-response curves were obtained by giving the full dose of agonist in microliter amounts to achieve the final concentration; no cumulative dose-response curves were obtained. $\mathrm{KCl}$ dose-response curves were obtained by draining the baths of normal PSS and substituting PSS with the desired concentration of $\mathrm{KCl}$.
Nifedipine. Nifedipine was added to the baths in microliter amounts to achieve a final concentration of $10^{-6} \mathrm{M}$. After a 5-min equilibration period, the muscle strips were contracted with either ACh $\left(10^{-4} \mathrm{M}\right)$ or BETH $\left(10^{-4} \mathrm{M}\right)$. The effects of nifedipine on the $\mathrm{KCl}$-induced contractions were studied by adding nifedipine to the baths to achieve a final concentration of $10^{-6} \mathrm{M}$. The baths were drained and replaced with PSS containing $80 \mathrm{mM} \mathrm{KCl}$ and nifedipine $\left(10^{-6} \mathrm{M}\right)$.

Zero- $\mathrm{Ca}^{2+}$ PSS. The muscle strips were tested in the zero- $\mathrm{Ca}^{2+}$ PSS by preadding either ACh (final concentration: $10^{-4} \mathrm{M}$ ) or BETH (final concentration: $10^{-4} \mathrm{M}$ ) to a zero- $\mathrm{Ca}^{2+}$ PSS and adding this solution to the muscle bath drained of normal PSS.

Contribution of force generated by intracellular $\mathrm{Ca}^{2+}$ sources. In an attempt to determine the contribution of the intracellular $\mathrm{Ca}^{2+}$ sources to total contractile force, we developed the following method (Fig. 1). Nifedipine was added to the baths to achieve a final concentration of $10^{-6} \mathrm{M}$. After $2 \mathrm{~min}$, the normal PSS was drained and quickly replaced with PSS containing $80 \mathrm{mM} \mathrm{KCl}$ and nifedipine $\left(10^{-6} \mathrm{M}\right)$. In the presence of nifedipine, the PSS containing $80 \mathrm{mM} \mathrm{KCl}$ failed to elicit a contractile response. Because $\mathrm{KCl}$ elicits cell membrane depolarization (11) and allows influx of extracellular $\mathrm{Ca}^{2+}$, the inhibition of contraction demonstrated the blockage of extracellular $\mathrm{Ca}^{2+}$ influx by the nifedipine. After $3 \mathrm{~min}$ (total $5 \mathrm{~min}$ of incubation in nifedipine), the muscle strips were contracted with ACh $\left(10^{-4} \mathrm{M}\right)$. The contraction induced by the ACh was assumed to represent the contribution of intracellular $\mathrm{Ca}^{2+}$ sources to the contractile response. The resultant contraction was expressed as a percentage of a control ACh response obtained immediately before the described protocol.

In the nifedipine and zero- $\mathrm{Ca}^{2+}$ protocols, results were expressed as a percentage of the control response obtained in normal PSS using the same techniques. Significant differences $(p<0.05)$ for all experiments were determined using the unpaired $t$ test, and results were expressed as the mean \pm SEM.

\section{RESULTS}

\section{Force Generation}

Response to ACh stimulation. Muscle strips from the gastric fundus from adult and fetal animals responded to increasing concentrations of $\mathrm{ACh}$ in a dose-dependent

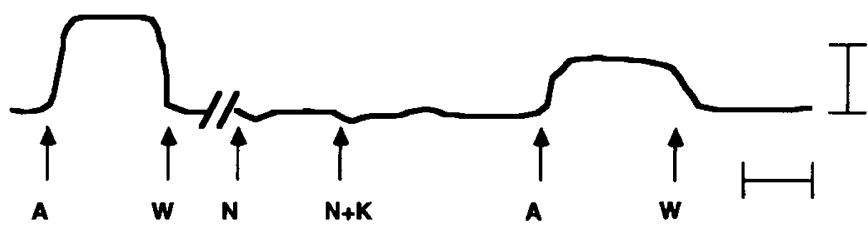

Figure 1. Reproduction of method used for contribution of force from intracellular $\mathrm{Ca}^{2+}$ sources as described in text: adult strip. The initial ACh contraction represents a control contraction. Calibration bars: horizontal, $1 \mathrm{~min}$; vertical, 1.0 g. $A, 10^{-4} \mathrm{M}$ ACh; $W$, wash; $N$, nifedipine $10^{-6} \mathrm{M} ; N+K$, nifedipine $10^{-6} \mathrm{M}$ and $\mathrm{KCl} 80 \mathrm{mM}$. 


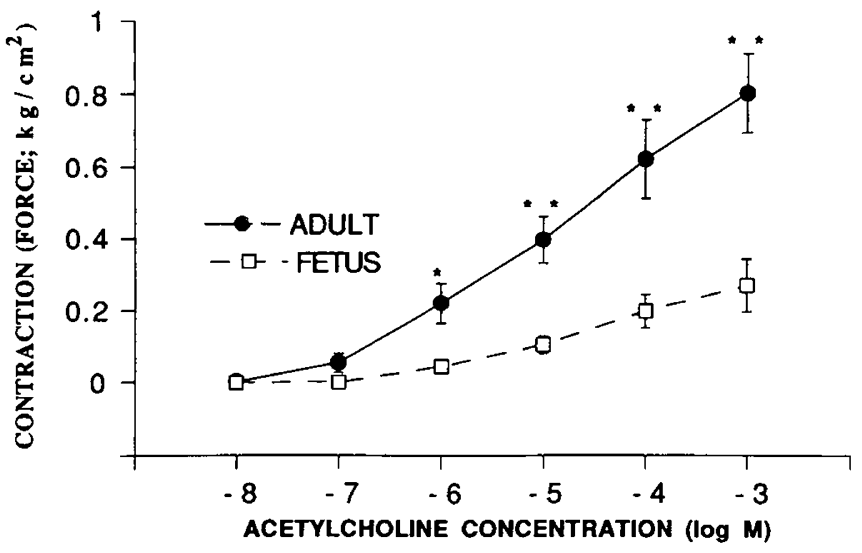

Figure 2. Dose-response curves for $\mathrm{ACh}$ on gastric fundus smooth muscle strips from fetal and adult guinea pigs. Each point represents the mean \pm SEM of at least seven muscle strips from four animals. *, Significantly different from fetus, $p<0.05$; $^{* *}$, significantly different from fetus, $p<0.01$.

fashion (Fig. 2). At each concentration above $10^{-7} \mathrm{M} \mathrm{ACh}$, the force developed per cross-sectional area of tissue by the adult muscle strips was significantly greater than the force developed by the muscle strips from the fetal animals. The maximal response in each group occurred at an ACh concentration of $10^{-3} \mathrm{M}$ and was $0.80 \pm 0.11 \mathrm{~kg} / \mathrm{cm}^{2}$ for the adult and $0.27 \pm 0.07 \mathrm{~kg} / \mathrm{cm}^{2}$ for the fetus $(p<0.01)$.

Response to BETH stimulation. Fundic smooth muscle also responded to BETH with a dose-dependent increase in force for both the adult and fetal animals (Fig. 3). The force developed by the adult animals was significantly greater at each concentration above $10^{-7} \mathrm{M}$. The maximal response in each group occurred at $10^{-4} \mathrm{M}$ and was $1.15 \pm 0.09 \mathrm{~kg} / \mathrm{cm}^{2}$ for the adult and $0.40 \pm 0.11 \mathrm{~kg} / \mathrm{cm}^{2}$ for the fetus $(p<0.01)$.

Response to $\mathrm{KCl}$ stimulation. Muscle strips from the fundus in the adult guinea pigs demonstrated increased force development in response to increasing concentration of $\mathrm{KCl}$, with the maximal response of $1.3 \pm 0.15$ $\mathrm{kg} / \mathrm{cm}^{2}$ occurring at a $\mathrm{KCl}$ dose of $80 \mathrm{mM}$ (Fig. 4). Tissues from the adult animals developed significantly more force than the fetal animals in response to $\mathrm{KCl}$ stimulation at

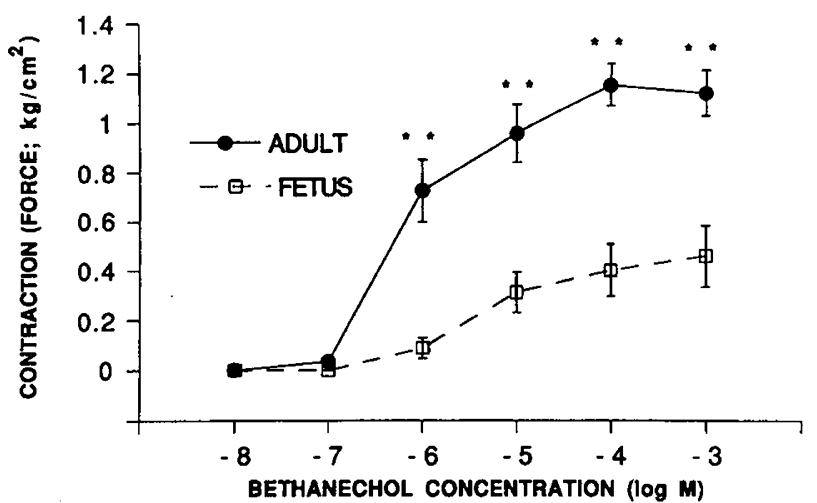

Figure 3. Dose-reponse curves for BETH on gastric fundus smooth muscle strips from fetal and adult guinea pigs. Each point represents the mean \pm SEM of at least five muscle strips from three animals. ${ }^{* *}$, Significantly different from fetus, $p<0.01$.

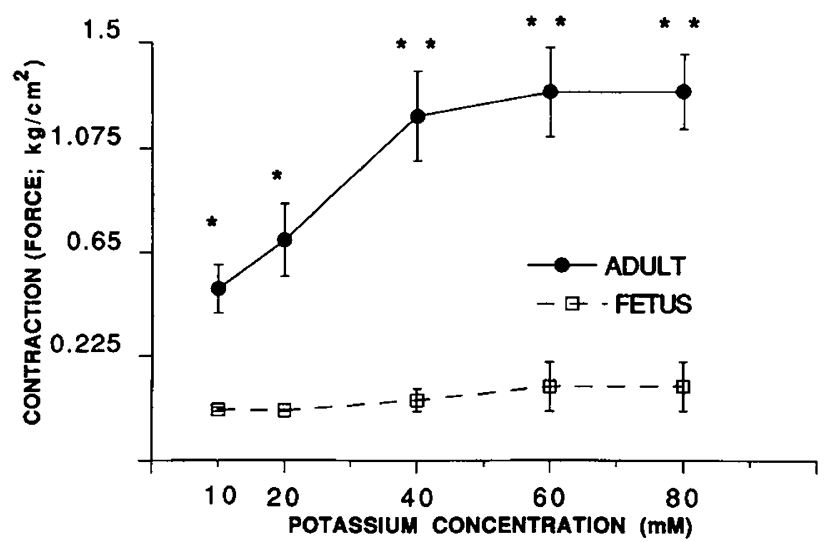

Figure 4. Dose-response curves for $\mathrm{KCl}$ on gastric fundus smooth muscle strips from fetal and adult guinea pigs. Each point represents the mean \pm SEM of at least nine muscle strips from three animals. *, Significantly different from fetus, $p<0.005 ;{ }^{* *}$, significantly different from fetus, $p<0.0001$.

each dose tested (10 to $80 \mathrm{mM})$. The fetal muscle strips were relatively unresponsive to the cell membrane depolarization induced by $\mathrm{KCl}$, with no response at 10 and 20 $\mathrm{mM}$ and a maximal response of only $0.10 \pm 0.04 \mathrm{~kg} / \mathrm{cm}^{2}$ occurring at a concentration of $80 \mathrm{mM}$.

\section{$\mathrm{Ca}^{2+}$ Utilization}

Zero- $\mathrm{Ca}^{2+}$ PSS. Contraction in zero- $\mathrm{Ca}^{2+}$ PSS produced a significantly smaller percentage of control force in the adult strips than in the fetal muscle strips with both ACh $(74.1 \pm 3.4$ versus $85.9 \pm 4.6 \%$ of control, respectively; $p<0.05)$ and BETH $(73.9 \pm 3.0$ versus $99 \pm 1.0 \%$ of control, respectively; $p<0.001$ ) (Fig. 5).

Nifedipine. Contraction in the presence of nifedipine also produced a significantly smaller percentage of control force in the adult animals than in the fetal animals in response to $\mathrm{ACh}(39.3 \pm 3.1$ versus $59.7 \pm 6.0 \%$ of control, respectively; $p<0.01)$, BETH $(40.1 \pm 2.6$ versus $53.5 \pm 4.5 \%$ of control, respectively; $p<0.05$ ) (Fig. 6 ), and $\mathrm{KCl}(1.3 \pm 0.93$ versus $10.6 \pm 4.5 \%$ of control, respectively; $p<0.05)$.

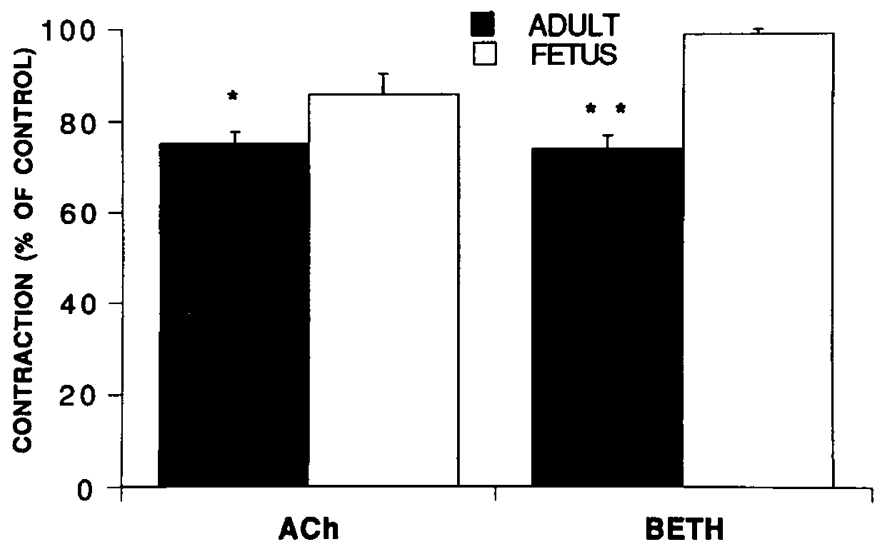

Figure 5. Contraction of the adult and fetal muscle strips with BETH and $\mathrm{ACh}$ in a zero- $\mathrm{Ca}^{2+}$ PSS. Each bar represents the mean \pm SEM of at least eight muscle strips from three animals. ${ }^{*}$, Significantly different from fetus, $p<0.05$; $^{* *}$, significantly different from fetus, $p<0.001$. 


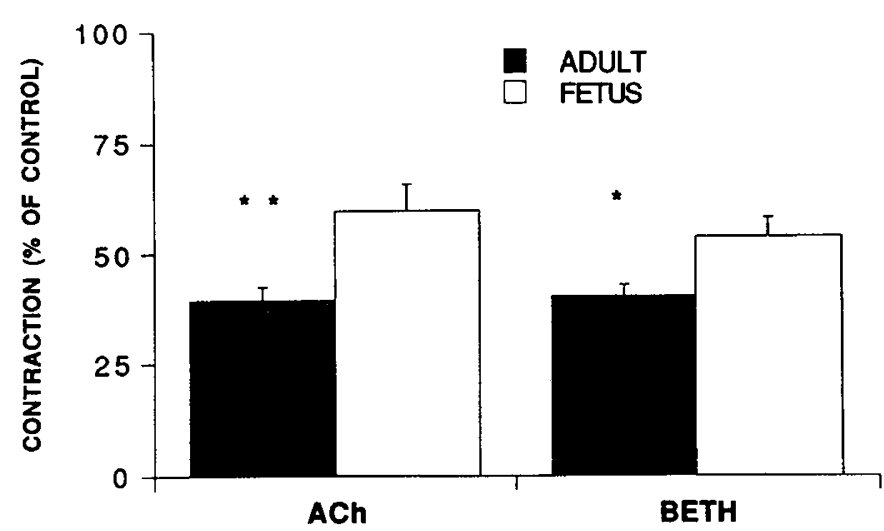

Figure 6. Contraction of the adult and fetal muscle strips with BETH and $\mathrm{ACh}$ in the presence of nifedipine. Each bar represents the mean \pm SEM of at least 15 muscle strips from three animals. *, Significantly different from fetus, $p<0.05 ;{ }^{* *}$, significantly different from fetus, $p<$ 0.01 .

Contribution of force from intracellular $\mathrm{Ca}^{2+}$ sources. Similar to the ACh dose-response experiments, the adult control strips generated more force than the fetal control strips (adult: $0.8 \pm 0.1 \mathrm{~kg} / \mathrm{cm}^{2}$; fetal: $0.1 \pm 0.04 \mathrm{~kg} / \mathrm{cm}^{2} ; p$ $<0.0005)$. However, when the contribution of intracellular $\mathrm{Ca}^{2+}$ sources was analyzed, the percentage of contraction attributed to intracellular $\mathrm{Ca}^{2+}$ was less in the adult tissues than in the fetal tissues $(33.3 \pm 2.0 \%$ compared with $44.2 \pm 4.7 \%$ of control, respectively; $p<0.05$ ) (Fig. 7).

\section{DISCUSSION}

The purpose of this study was to compare the contractile response in the gastric fundus of fetal and adult guinea pigs. The fetal animals were used to correlate with human preterm infants, which frequently have gastric motor dysfunction. Both receptor-dependent (ACh and $\mathrm{BETH})$ and receptor-independent agonists $(\mathrm{KCl})$ were used to fully investigate the extent of the postnatal development of force. Regardless of the mechanism of action of the agonist, muscle strips from the adult animals developed significantly more active force than tissues from the fetal animals, suggesting that the postnatal in-

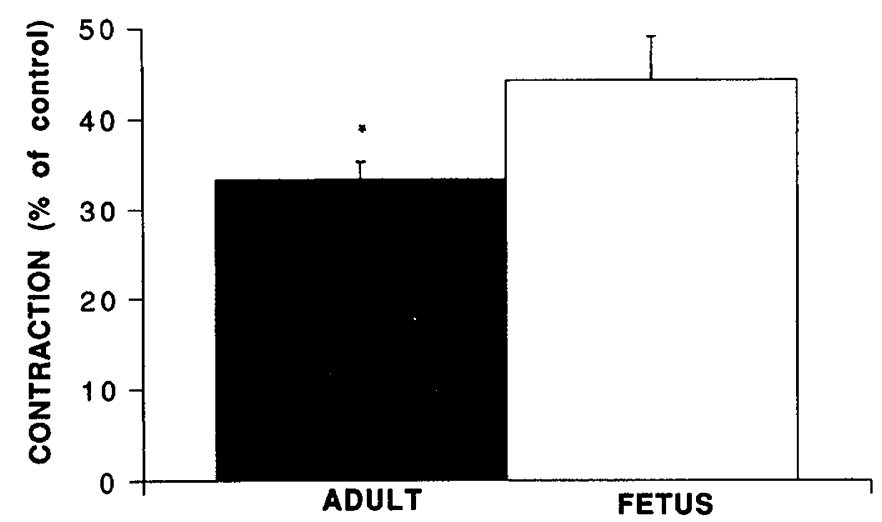

Figure 7. Results from the contribution of force from intracellular $\mathrm{Ca}^{2+}$ sources. Each bar represents the mean \pm SEM of at least nine muscle strips from three animals. ${ }^{*}$, Significantly different from fetus, $p<0.05$. crease in contractility is due, in part, to factors independent of membrane activation. Our results are consistent with numerous other reports of postnatal maturation of visceral smooth muscle $(3-6,12-15)$.

The greater contractile response of the adult tissues to $\mathrm{KCl}$, which leads to contraction through membrane depolarization and influx of extracellular $\mathrm{Ca}^{2+}$ through voltage-dependent $\mathrm{Ca}^{2+}$ channels, indicates an increased reliance on extracellular $\mathrm{Ca}^{2+}$ by the adult gastric fundus. Conversely, the lack of responsiveness of the fetal tissues to $\mathrm{KCl}$ implies a relative inability of the fetal fundus to utilize extracellular $\mathrm{Ca}^{2+}$ through voltage-dependent $\mathrm{Ca}^{2+}$ channels. The limited response of antral smooth muscle of young animals to $\mathrm{KCl}$ stimulation has previously been reported in the rabbit (3). Additional support for the enhanced ability of the adult fundus to utilize extracellular $\mathrm{Ca}^{2+}$ is provided by the diminution of force seen in the adult in the presence of nifedipine and in a zero- $\mathrm{Ca}^{2+}$ PSS compared with the fetus. Furthermore, the results from the contribution of force from intracellular $\mathrm{Ca}^{2+}$ sources confirm that the contractions generated by the adult animals were less dependent on intracellular $\mathrm{Ca}^{2+}$ sources.

The development of increasing force in the gastric fundus is a complex process that may be dependent on factors both at the level of the cell membrane and at postmembrane sites. This was demonstrated by the increased force generation by the adult tissues in response to both receptor-dependent stimulation and receptorindependent stimulation. We have previously demonstrated that postnatal maturation of force in smooth muscle from the rabbit antrum may also be dependent on factors at the level of the cell membrane and beyond (3). Hillemeier et al. (6) hypothesized that the distal antrum of the kitten may not contract fully because of immature intracellular $\mathrm{Ca}^{2+}$ utilization. However, they demonstrated no difference in $\mathrm{Ca}^{2+}$ use in the fundus between the kitten and adult. In contrast, Hyman et al. (4) suggested that diminished contractility in the antrum of newborn rabbits may be secondary to a paucity of $\mathrm{Ca}^{2+}$ channels needed to support $\mathrm{Ca}^{2+}$ influx but demonstrated no difference in $\mathrm{Ca}^{2+}$ utilization in the fundus.

Although Hillemeier et al. and Hyman et al. have previously demonstrated that both the adult and newborn fundus rely on extracellular $\mathrm{Ca}^{2+}$ for contraction, the difference may be explained by interspecies variation and their use of newborn animals compared with our use of a fetal model. The third-trimester fetal animals were used to best approximate a preterm model.

As a note of caution, we cannot rule out the possibility that differences in the size, mass, or geometric arrangements of the muscle bundles in tissues from fetal and adult animals may also have contributed to the observed differences in force. This study was not designed to characterize the properties of the contractile proteins. It is possible that the difference in force between the fetal and adult tissues may be secondary to the number of contractile proteins or a difference in activation of the 
contractile response or activation of the contractile proteins. This was demonstrated with the data from the contribution of force from intracellular $\mathrm{Ca}^{2+}$ sources, in which the percentage of contribution of intracellular $\mathrm{Ca}^{2+}$ to the contractile response was greatest in the fetus, but the absolute magnitude of the contractile response was greatest in the adult. The observed difference in contractility between the adult and fetal animals, seen with this methodology, is consistent with the other data indicating an increase in extracellular $\mathrm{Ca}^{2+}$ use by the adult muscle. However, the difference demonstrated by this methodology may be partly explained by a discrepancy in the activation of receptor-operated $\mathrm{Ca}^{2+}$ channels between the two age groups.

In summary, our results suggest that the adult gastric fundus generates more active force per cross-sectional area of tissue than the fetal gastric fundus. This developmental change may be the result of increased utilization of extracellular $\mathrm{Ca}^{2+}$, in part through voltage-dependent $\mathrm{Ca}^{2+}$ channels. The functional implications of the data remain to be settled. However, the gastric fundus serves to generate a pressure gradient that is important for the emptying of liquids (16) and is thus an important part of the mechanism for gastric emptying in preterm infants. Although it is difficult to extrapolate in vitro data to in vivo function, the physiologic differences demonstrated between the fetal and adult animals in this study may partly explain the difficulty in feeding immature infants.

Acknowledgments. The authors thank Rita Garbarino and John Martin, Ph.D., for their technical assistance and
S. David Rubenstein, M.D., for his thoughtful review of the manuscript.

\section{REFERENCES}

1. Signer E, Fridrich R 1975 Gastric emptying in newborn and young infants. Acta Paediatr Scand 64:525-530

2. Seigel M 1983 Gastric emptying time in premature and compromised infants. J Pediatr Gastroenterol Nutr 2(suppl 1):s136-s140

3. Zitterman J, Ryan JP 1990 Development of gastric antral smooth muscle contractility in newborn rabbits. Am J Physiol 21:G571-G575

4. Hyman PE, Martin MG, Tomomasa T, Jing J, Snape WJ 1989 Development of calcium channels in gastric smooth muscle. Pediatr Res 25:600-604

5. Tomomasa T, Yagi H, Kimura S, Snape WJ, Hyman PE 1989 Developmental changes in agonist-mediated gastric smooth muscle contraction in the rabbit. Pediatr Res 26:459-461

6. Hillemeier AC, Bitar KN, Biancani P 1991 Developmental characteristics of the kitten antrum. Gastroenterology 101:339-343

7. Ryan JP, Bhojwani A, Wang MB 1987 Effect of pregnancy on gastric motility in vivo and in vitro in the guinea pig. Gastroenterology 93:29-34

8. Herlihy JT, Murphy RA 1973 Length-tension relationship of smooth muscle of the hog carotid artery. Circ Res 33:275-283

9. Ryan JP 1984 Effect of pregnancy on gallbladder contractility in the guinea pig. Gastroenterology 87:674-678

10. Renzetti LM, Wang MB, Ryan JP 1990 Contribution of intracellular calcium to gallbladder smooth muscle contraction. Am J Physiol 259:G1-G5

11. Bitar KN, Burgess GM, Putney JW, Makhlouf GM 1986 Source of activator calcium in isolated guinea pig and human gastric muscle cells. Am $\mathrm{J}$ Physiol 250:G280-G286

12. Lambert R, Ryan JP 1990 Response to calcium of skinned gallbladder smooth muscle from newborn and adult guinea pigs. Pediatr Res 28:336-338

13. Panitch HB, Allen JL, Ryan JP, Wolfson MR, Shaffer TH 1989 A comparison of preterm and adult airway smooth muscle mechanics. J Appl Physiol 66:1760-1765

14. Yagi H, Snape WJ, Hyman PE 1991 Developmental changes in agonistmediated colonic smooth muscle contraction in the rabbit. Pediatr Res 29:20-23

15. Yagi H, Snape WJ, Hyman PE 1991 Perinatal changes in bombesin-stimulated muscle contraction in rabbit stomach and colon. Gastroenterology 100:980 985

16. Kelly KA 1980 Gastric emptying of liquids and solids: roles of proximal and distal stomach. Am J Physiol 239:G71-G76 